\title{
ERICO VERISSIMO E PEPETELA: DIFERENTES TRAJETÓRIAS LITERÁRIAS QUE CONVERGEM
}

\section{ERICO VERISSIMO AND PEPETELA: DIFFERENT LITERARY TRAJECTORIES THAT CONVERGE}

\author{
Donizeth Aparecido Campolin dos Santos* \\ https://orcid.org/0000-0002-5434-2124. \\ FATEB/UEPG
}

\begin{abstract}
Resumo: Os projetos literários dos romancistas Erico Verissimo e Artur Carlos Maurício Pestana dos Santos, conhecido como Pepetela, filiam-se à tradição da literatura de intervenção social, nos moldes como foi configurada no século XX, pois comportam um projeto ético fiel às suas visões de mundo e aos seus compromissos social e humano, que é intensificado pelo projeto estético que os acompanha. Nesse sentido, há afinidades ideológicas e estéticas entre os dois romancistas com a confluência, no plano ideológico, da ideologia humanista e do compromisso social e humano que ambos apresentam em seus projetos literários, e no plano estético, da semelhança existente entre as estruturas narrativas de seus romances de fundação (a trilogia $O$ tempo e o vento, de Erico Verissimo, e Yaka e Lueji, de Pepetela), pelo fato de os dois escritores se utilizarem de temáticas e estratégias narrativas comuns, tais como a saga familiar, a metaficção, a técnica narrativa do contraponto e a polifonia. Assim, acredita-se que a afinidade ideológica existente entre Pepetela e Erico Verissimo levou o escritor angolano a incorporar ao seu projeto literário alguns elementos temáticos e formais utilizados pelo brasileiro, segundo o conceito de intertextualidade de Julia Kristeva (1974), que concebe a escrita de um texto literário como a leitura do corpus anterior. No entanto, a relação entre eles não se alimenta apenas na semelhança nos pontos em comum, mas também nas diferenças que há entre suas obras e entre seus projetos literários.
\end{abstract}

Palavras-Chave: Literaturas de língua portuguesa. Literatura engajada. Narrativas de fundação. Erico Verissimo. Pepetela.

\begin{abstract}
The literary projects of the novelists Erico Verissimo and Artur Carlos Maurício Pestana dos Santos, known as Pepetela, affiliate themselves with the tradition of social intervention literature, in the same manner as it was configured in the 20th century, as they comprise an ethical project faithful to their world views and their social and human commitments, which is
\end{abstract}

\footnotetext{
* Doutor em Letras (Estudos Comparados de Literaturas de Língua Portuguesa) pela Universidade de São Paulo (USP), professor de Língua Portuguesa da Faculdade de Telêmaco Borba (FATEB) e professor colaborador da Universidade Estadual de Ponta Grossa (UEPG). E-mail: <donizeth.santos@hotmail.com>.
} 
intensified by the aesthetic project that accompanies it. In this sense, there are ideological and aesthetic affinities between the two novelists with the confluence, on the ideological plane, of the humanist ideology and the social and human commitment that both present in their literary projects, and on the aesthetic plane, of the similarity between the narrative structures of their founding novels (the trilogy O tempo e o vento, by Erico Verissimo, and Yaka and Lueji, by Pepetela), due to the fact that the two writers use common themes and narrative strategies, such as the family saga, metafiction, counterpoint narrative technique and polyphony. Thus, we believe that the ideological affinity between Pepetela and Erico Verissimo led the Angolan writer to incorporate into his literary project some thematic and formal elements used by the Brazilian, according to the concept of intertextuality by Julia Kristeva (1974), who conceives the writing of a literary text as a reading of the preceding corpus. However, the relationship between them is based not only on the similarity in their common traits, but also on the differences that exist between their works and between their literary projects.

Keywords: Portuguese language literature. Engaged literature. Foundational narratives. Erico Verissimo. Pepetela.

\section{Introdução}

O romancista brasileiro Erico Verissimo e o angolano Artur Carlos Maurício Pestana dos Santos (Pepetela) são escritores engajados, comprometidos com as causas humanas e contrários a qualquer tipo de repressão, violência e cerceamento de liberdade, e, por isso, seus projetos literários comportam, acima de tudo, um projeto ético fiel às suas visões de mundo e aos seus compromissos social e humano, que é intensificado pelo projeto estético que os acompanha, de modo que ambos conseguem aliar literatura de intervenção social com alta elaboração estética. Desse modo, para eles, a escrita literária é uma ação que visa “[...] representar o mundo e testemunhar sobre ele” (SARTRE, 2006, p. 47), recuperando-o e mostrando-o tal como ele é, para desvendá-lo e oferecê-lo à reflexão do leitor, com os objetivos de testemunhar e explorar o paradoxo que é o homem no mundo, conforme a assertiva de Jean-Paul Sartre (2006) em relação ao papel do escritor, e promover a liberdade humana e o conhecimento, conforme a observação feita por Edward Said (2005) sobre a função social do intelectual.

Sob esse aspecto, os textos literários de Erico Verissimo e Pepetela possuem uma função social, que é ao mesmo tempo humanizadora e política, pois buscam oferecer ao leitor, além da fruição da boa história contada, algo que possa despertar consciências e colaborar para a ocorrência de significativas mudanças sociais que, por sua vez, possam contribuir para o bem-estar do homem. Por isso, eles colocam em suas obras literárias o conjunto dos valores nos quais acreditam e pelos quais se definem (DENIS, 2002).

Nesse sentido, lembramos duas declarações dadas pelos dois romancistas sobre a escrita literária, que corroboram o que afirmamos anteriormente. Erico Verissimo, numa entrevista concedida a Jorge Andrade, expõe o seu ponto de vista sobre o papel do romancista: 
Sempre achei que o menos que um escritor pode fazer, numa época de violência e injustiças como a nossa, é acender a sua lâmpada, fazer luz sobre a realidade de seu mundo, evitando que sobre ele caia a escuridão, propícia aos ladrões e aos assassinos. Segurar a lâmpada, a despeito da náusea e do resto. Se não tivermos uma lâmpada elétrica, acendamos o nosso toco de vela ou, em último caso, risquemos fósforos repetidamente, como um sinal de que não desertamos nosso posto. (ANDRADE, 1972, p. 9).

Já Pepetela, em entrevista concedida à professora Jane Tutikian, ao ser questionado sobre a confluência entre literatura e ideologia e o papel do escritor, responde:

Não me parece possível o escritor separar a sua ideologia da sua prática de escritor. É claro que se pode pôr na boca dos personagens tudo o que se queira e a literatura em parte é isso mesmo, uma discussão/confronto entre personagens de ideologias diferentes, mesmo se elas não sabem o que isso quer dizer. Mesmo os escritores mais desideologizados têm uma ideologia e um papel na sociedade. (TUTIKIAN, 2009, p. 209).

Dessa forma, são muitas as afinidades ideológicas entre Pepetela e Erico Verissimo, que, por sua vez, levaram também a uma afinidade estética entre os dois escritores na configuração de suas narrativas (romances) de fundação ${ }^{1}$, quais sejam: O tempo e o vento (1995), trilogia de Erico Verissimo formada pelos romances $O$ continente (1995f), O retrato (1995h) e O arquipélago (1995e); e os romances Yaka (1998) e Lueji, o nascimento dum império (1997), de Pepetela. ${ }^{2}$

Essas afinidades foram geradas pela nova articulação entre o elemento literário e o social, que, a partir das primeiras décadas do século XX, envolveu mais o aspecto político e tornou a literatura mais compromissada com a realidade que lhe dava origem, levando os escritores a “[...] uma tomada de posição refletida, consciência lúcida do escritor de pertencer ao mundo e vontade de mudá-lo” (DENIS, 2002, p. 37-38), diante de um contexto histórico desolador, de guerras e de crises sociais, como foi a primeira metade do século XX. E, assim, a literatura passou a ser também um meio de “tomar partido" contra todas as injustiças, violências e misérias que emergiam desse cenário caótico, tornando-se engajada, conforme teorizou Sartre (2006), criando-se, então, um novo modo de se fazer literatura de intervenção social, que, por sua vez, provocou um grande diálogo intertextual entre romancistas de todas as nacionalidades em razão da afinidade ideológica e dos laços de solidariedade gerados entre eles, proporcionando o compartilhamento de temáticas e estratégias narrativas que passaram a ser de uso comum.

É nessa tradição da literatura de intervenção social, nos moldes como foi configurada no século XX, que se filia a escrita literária de Erico Verissimo e Pepetela. O primeiro foi contemporâneo do surgimento dessa literatura, fazendo parte dos escritores engajados de língua portuguesa que foram formados na mesma atmosfera ideológica da frente popular antifascista que contagiou os intelectuais do mundo todo na década de 1930, conforme observa Benjamin

\footnotetext{
${ }^{1}$ Lúcia Helena (2005, p. 169) define a narrativa de fundação como “[...] um fenômeno híbrido, parte artístico-literário, parte históricopolítico, no qual, por meio da ficção, criam-se 'comunidades imaginadas’”, ou seja, uma narrativa que procura “[...] escrever a nação por meio da ficção, atribuindo-se correlações entre o localismo e nacionalismo” (HELENA, 2005, p. 179).

${ }^{2}$ As datas citadas entre parênteses após os títulos das obras são as das edições consultadas para a escrita do texto. No entanto, alertamos que o faremos somente na primeira vez em que a obra for citada; nas demais citações, aparecerá apenas o título, a não ser nos casos em que for citação textual direta ou indireta.
} 
Abdala Júnior (2007), sendo forjados num dos mais turbulentos períodos históricos que a humanidade teve. Já Pepetela, cuja carreira literária começa na década de 1960, podemos considerá-lo como herdeiro direto da tradição da literatura engajada em língua portuguesa, que começou no Brasil nos anos de 1930, chegou a Portugal na década seguinte e um pouco mais tarde serviu como modelo a ser seguido pelos escritores das nascentes literaturas de Angola, Cabo Verde e Moçambique, conforme atestam várias declarações de escritores portugueses e africanos, das quais destacamos a declaração feita por Pepetela em uma entrevista concedida ao jornalista e escritor Wilson Bueno, publicada no jornal O Estado de São Paulo em 2000 e reproduzida por Rita Chaves e Tania Macêdo no livro Portanto...Pepetela (2009), na qual o escritor angolano reconhece ter sido influenciado por vários romancistas brasileiros, entre os quais Erico Verissimo: "Reconheço grande influência dos escritores brasileiros que lia e relia quando muito jovem: Jorge Amado, Graciliano Ramos, José Lins do Rego, Erico Verissimo. Foram os meus mestres. Dos atuais, destaco João Ubaldo Ribeiro, entre muitos que admiro" (BUENO, 2000 apud CHAVES; MACÊDO, 2009, p. 36).

Nesse sentido, concordamos inteiramente com a afirmação feita pelo professor Edvaldo Bergamo (2008, p. 199) de que “[...] o projeto literário dos anos 30 e 40 do século XX de revalorização do realismo e de aprofundamento da questão social [...] deixou marcas que foram aproveitadas e/ou reformuladas pela posteridade”. Pois, conforme afirma Julia Kristeva (1974), amparando-se na teoria do dialogismo de Mikhail Bakhtin, a escrita de um texto literário é a leitura do corpus literário anterior, noção que implica ver o texto como absorção e réplica a outro texto. Assim, o texto literário situa-se numa corrente histórica e social, constituída por textos que o escritor lê e na qual se insere ao reescrevê-los.

Dentre as marcas deixadas pelos romancistas engajados de língua portuguesa dos anos de 1930 e 1940 que foram aproveitadas e/ou reformuladas pela posteridade estão, a nosso ver, algumas marcas temáticas e formais da literatura do romancista brasileiro (a narrativa de fundação, a saga familiar, a metaficção, o contraponto e a polifonia) que foram apropriadas, reformuladas e adaptadas pelo escritor angolano ao seu projeto literário e ao contexto da literatura angolana.

Dessa forma, acreditamos que a afinidade ideológica existente entre Pepetela e Erico Verissimo levou o escritor angolano a incorporar ao seu projeto literário alguns elementos temáticos e formais utilizados pelo escritor brasileiro. No entanto, a relação entre eles não se alimenta apenas na semelhança nos pontos em comum, mas também nas diferenças que há entre suas obras. A começar por seus projetos literários, que são construídos de acordo com o contexto histórico-social em que estão inseridos, pois, lembrando importante observação feita por Antonio Candido (1972, 2000), o texto literário se forma a partir do contexto, que dá "lastro às obras e as amarram ao mundo onde vivemos” (CANDIDO, 1972, p. 79), de forma que uma obra literária é fruto da confluência entre a iniciativa individual do escritor e as condições sociais do ambiente em que está inserido.

Desse modo, à parte a grande afinidade que há entre os dois escritores, com a confluência, no plano ideológico, da ideologia humanista e do compromisso social e humano que ambos apresentam em seus projetos literários, e, no plano estético, da semelhança existente entre as estruturas narrativas de seus romances de fundação, através do uso de temáticas e estratégias narrativas comuns, a matéria literária abordada em seus romances, mesmo naqueles em que há confluência estética, é totalmente diversa, sendo também que os seus projetos literários apresentam significativas diferenças em relação ao desenvolvimento. 


\section{Erico Verissimo e Pepetela: projetos literários}

Erico Verissimo inicia a sua trajetória literária nos anos de 1930 procurando a melhor forma de "realizar um corte transversal da sociedade" (BRAGA, 1997, p. 31), através do qual pudesse revelar ao leitor a engrenagem social e seus mecanismos, de modo que mostrasse o homem na sua dinâmica social e o indivíduo em sua humanidade (CHAVES, 2001). Por essa razão, os seus primeiros romances ${ }^{3}$ são ambientados em cenários urbanos, seja em Porto Alegre ou na fictícia Jacarecanga, espaços que lhe permitia transitar por diversos estratos sociais, desde as classes mais baixas até as mais abastadas, embora o escritor se fixasse mais na representação da classe média baixa, cujas preocupações se baseavam na questão econômica que impunha dificuldades à sua sobrevivência. Conforme o próprio escritor reconhece, as personagens dos seus primeiros livros preocupavam-se com as contas a pagar no fim do mês, o que, na verdade, era um reflexo da própria condição socioeconômica do autor, que na época se desdobrava em várias atividades durante mais de 12 horas por dia para poder sobreviver, tendo apenas os finais de semana para escrever os seus livros (BORDINI, 1997).

O forte questionamento político vai figurar na obra literária de Erico Verissimo somente a partir de O tempo e o vento ${ }^{4}$, principalmente a partir do terceiro volume, O arquipélago (1995e), e também, não por coincidência, após o escritor ocupar o cargo de Diretor do Departamento de Assuntos Culturais da União dos Estados Americanos (UEA), no período de 1953 a 1956, condição que colaborou para o seu amadurecimento político, principalmente por propiciar ao autor a vivência de situações políticas de bastidores, de ver o poder do lado de dentro, fato que certamente ajudou na elaboração de romances de forte conteúdo político, como se pode verificar nas suas últimas produções literárias 5 .

Dessa forma, o projeto literário de Erico Verissimo, que apresenta uma visível linha de coerência do início ao fim, vai se desenvolvendo e incorporando outros elementos, tanto formais quanto de conteúdo, na medida em que o contexto sócio-histórico muda e o autor vai tendo outras vivências, e, em consequência, ele vai obtendo uma visão política mais alargada. Exemplos disso são os fatos de que Erico Verissimo só empreendeu a elaboração de $O$ tempo e o vento, se aventurando pela história da origem do Rio Grande do Sul, somente quando se sentiu suficientemente amadurecido para realizar tal tarefa; e também, ele que sempre teve um verdadeiro horror à violência, passar a aceitar a violência contra a violência (a violência necessária), conforme fica nítido em $O$ senhor embaixador, quando ele engaja na luta armada os intelectuais Leonardo Gris e Pablo Ortega. Nesse aspecto, no contexto do seu projeto literário, a trilogia $O$ tempo e o vento ocupa uma posição central, como obra do amadurecimento do escritor que faz uma transição para um discurso político mais radical. Nesse sentido, podemos afirmar que Erico Verissimo inicia a sua trajetória com obras mais preocupadas com o aspecto social, passando para a preocupação histórica da formação do estado do Rio Grande do Sul, até chegar ao questionamento político nacional e internacional.

\footnotetext{
${ }^{3}$ Clarissa (1995b), Caminhos cruzados (1995a), Música ao longe (1995d) e Um lugar ao sol (1995k).

${ }^{4}$ Há uma pequena exceção: na primeira parte do romance Saga (1995j), publicado em 1940, Erico Verissimo dá um forte tom político ao narrar a participação da personagem Vasco Bruno na Guerra civil espanhola, mas na segunda parte do romance o autor abandona essa abordagem política e retoma a abordagem social.

${ }^{5}$ O senhor embaixador (1995i), O prisioneiro (1995g) e Incidente em Antares (1995c).
} 
Já em relação à Pepetela, de maneira inversa à trajetória literária de Erico Verissimo, em que o elemento político vai gradativamente sendo incorporado à sua obra literária até se tornar o elemento predominante nos seus três últimos romances, o escritor angolano já inicia a sua carreira literária, produzindo uma literatura em que o "milieu político é o cenário dominante" (HOWE, 1998, p. 5), ou seja, ele já nasce escritor como um romancista em que o questionamento político é um elemento fundamental em sua obra. A razão disso é que o contexto histórico-político-social no qual Pepetela estava inserido era totalmente diverso do contexto vivido por Erico Verissimo. Ele vivia num país que ainda era uma colônia portuguesa e por isso havia a necessidade de uma descolonização urgente e do engajamento, não só literário mas também político, para a libertação nacional. Dessa forma, a guerra contra o colonialismo português e o discurso anticolonial vão pautar as primeiras obras literárias do seu projeto literário, cujo tema principal é a nação angolana, acompanhado de um constante questionamento às estruturas de poder tanto coloniais quanto pós-independência. E ao contrário de Verissimo, que só no final de sua trajetória literária incorpora a violência necessária aos seus romances, em Pepetela ela está presente desde o início, como único meio de libertar Angola do jugo colonial português.

Desse modo, Pepetela surge como escritor no período de reivindicação da independência política angolana; e como personagem atuante nesse processo histórico, estando totalmente engajado na causa revolucionária, os seus primeiros romances foram escritos para não serem publicados e tinham um cunho totalmente didático, seja para ser utilizado como texto de reforço no ensino da língua portuguesa nas escolas do Movimento Popular de Libertação de Angola (MPLA), caso de As aventuras de Ngunga (1981), seja para servir de instrumento de reflexão política do próprio escritor para auxiliá-lo nas aulas de formação política que ministrava aos guerrilheiros, como foi o caso de Mayombe (1982), quando estava atuando diretamente no front da guerra colonial. Naquele momento, o romance de caráter político atendia melhor a uma necessidade didática urgente daquele contexto histórico e correspondia também a uma tomada de posição diante daquela realidade vivida, que durou cerca de 14 anos, período em que Pepetela viveu em situação de diáspora e guerrilha.

Somente alguns anos após a independência política de Angola, depois do autor ter deixado o cargo de vice-ministro da Educação, é que ele pôde começar a pensar a sério o seu fazer literário como uma atividade sistematizada que poderia ser escrita para ser publicada. Aí então é que surgem as narrativas (romances) de fundação em seu projeto literário. Após essa estabilização do autor, e em certa medida do próprio país ${ }^{6}$, Pepetela transita entre romances históricos (que também são de fundação), políticos, alegóricos e satíricos, e à exceção de $O$ terrorista de Berkeley (2007), Califórnia (2007) e O quase fim do mundo (2008) todos eles têm Angola como tema e cenário, ao mesmo tempo em que mantêm o questionamento político como uma espécie de eixo norteador do projeto literário do autor, objetivando levar o seu leitor a pensar a construção de Angola.

Nesse sentido, o projeto literário de Pepetela difere totalmente do projeto literário de Erico Verissimo, pois o projeto literário do escritor angolano já se inicia com uma consistente conscientização política que o atravessa do início ao fim, enquanto que o escritor gaúcho só adquire uma conscientização política mais sólida a partir da escrita de O tempo e o vento. Outra

\footnotetext{
${ }^{6}$ Em certa medida porque, após a independência de Angola, ocorrida em 1975, o país conviveu com uma guerra civil que só terminou em 2002.
} 
diferenciação é que Erico Verissimo prioriza em seus romances a abordagem da sociedade, mas sem a preocupação da construção nacional, com exceção de $O$ tempo e o vento e em certa medida de Incidente em Antares, enquanto em Pepetela a abordagem da sociedade angolana e a construção da nação são inseparáveis.

Em relação à confluência estética entre a estrutura narrativa de O tempo e o vento e Yaka, elaboradas em forma de narrativas de fundação tendo por base a saga familiar, cabe dizermos também que a semelhança é apenas formal e temática. No plano do conteúdo predomina a diferença entre as duas narrativas de fundação. O conteúdo veiculado por $O$ tempo e o vento é uma matéria literária brasileira, que, centralizada na representação do Rio Grande do Sul, aborda aspectos da sociedade, da cultura e da história brasileira em total consonância com o projeto literário de Erico Verissimo. Do mesmo modo, podemos dizer que Yaka possui uma matéria literária 100\% angolana, representando aspectos importantes da história, da cultura e da sociedade angolana, também em perfeita consonância com o projeto literário de Pepetela.

Nesse sentido, vale lembrarmos uma observação feita por Antonio Candido (2004) sobre o fato de uma técnica narrativa poder ser utilizada por vários escritores. Para o crítico brasileiro, a técnica empregada é um instrumento de trabalho e por isso ela pode ser utilizada por mais de um escritor, de forma que os escritores podem usá-la para expressar mais de um conteúdo, ou seja, se a técnica ou a forma é semelhante, os conteúdos expressados por ela podem ser ou são diferentes. Ao encontro da observação de Candido vem o pensamento do crítico literário russo Victor Zhirmunsky (1994), para quem cada influência literária envolve a transformação social do modelo que é adotado, ou seja, a sua reinterpretação e adaptação às condições literárias e sociais, e à individualidade ideológica, psicológica e artística do autor em questão, de forma que, segundo Edvaldo Bergamo (2008), o compartilhamento da mesma série ideológica e de temas e estratégias formais semelhantes não impedem que a obra literária seja permeada por variantes locais, que devem ser observadas na comparação literária como elementos de diferenciação que a caracterizam.

Sob esse aspecto, cabe também lembrarmos outra observação feita por Antonio Candido (2004), desta vez sobre o fato de Erico Verissimo ter se apropriado e adaptado ao seu projeto literário e ao contexto da literatura brasileira algumas técnicas narrativas originárias das literaturas de língua inglesa e francesa. Segundo o crítico brasileiro, o fato de ele ter se apropriado delas não significa de forma alguma que tenha feito uma mera cópia, conforme muitos críticos acusavam o escritor na época.

Erico Verissimo é um escritor brasileiro que fez romance especificamente brasileiro, transpondo para o plano da arte, numa linguagem bem brasileira, temas, problemas, sentimentos e personagens que são essencialmente brasileiros. Os seus recursos técnicos, os seus ângulos de visão, é que sofrem a influência de escritores estrangeiros. (CANDIDO, 2004, p. 64).

Da mesma forma, podemos considerar Yaka como um romance legitimamente angolano, escrito em língua portuguesa e numa linguagem autenticamente angolana, abordando temas, problemas, sentimentos e personagens essencialmente angolanos, encaixados numa estrutura narrativa que apresenta muitos pontos em comum com a saga de Erico Verissimo. Desse modo, Yaka difere de O tempo e o vento por apresentar matéria literária e matéria de extração histórica 
angolanas, e o fato de Pepetela ter se utilizado de estratégias narrativas já utilizadas por outro escritor na sua elaboração não diminui em nada o seu valor literário e nem o torna inferior ou devedor à obra que lhe serviu de matriz. Nesse sentido, vejamos então alguns pontos que marcam diferenças entre Yaka e $O$ tempo e o vento.

\section{Yaka e 0 tempo e o vento: utilização do gênero da narrativa (romance) de fundação}

A narrativa de fundação escrita por Pepetela em 1983 e publicada em 1984, embora não seja a primeira em Angola ${ }^{7}$, praticamente inicia uma tradição dentro da literatura angolana, cujo principal representante vai ser o próprio autor, pois até o momento da escrita deste texto, além de Yaka, Pepetela já havia publicado mais três narrativas de fundação ${ }^{8}$. Nesse sentido, é possível também afirmarmos que esse gênero se torna uma tradição dentro do próprio projeto literário do escritor angolano, através do qual ele enceta uma busca pelo mito fundador da angolanidade, que possa construir/reconstruir a nação angolana.

Quanto à narrativa de fundação de Erico Verissimo, ela se insere numa tradição já existente na literatura brasileira, iniciada por José de Alencar em 1857, quando o escritor cearense publicou $O$ guarani, dando sequência ao gênero com as publicações posteriores de Iracema, Ubirajara e As minas de prata, e depois continuada no Modernismo brasileiro por Mário de Andrade com Macunaíma. E depois de O tempo e o vento, Erico Verissimo voltou ao gênero apenas parcialmente em Incidente em Antares, o último romance publicado pelo escritor gaúcho, em que, segundo Márcia Ivana de Lima e Silva (2000), o autor realizou uma paródia da própria trilogia. É importante ressaltar também que embora $O$ tempo e o vento adquira feições nacionais pelo diálogo que trava com a história e a política brasileira, a preocupação do autor ao escrever a obra é abordar a saga da formação do estado do Rio Grande do Sul, que é apenas uma parte da formação da nação brasileira.

Em relação à saga familiar, Pepetela utiliza essa estratégia narrativa da mesma forma que Erico Verissimo a utilizou em O tempo e o vento, centralizando a narrativa na história de uma família fictícia, mediana, que sintetiza as peculiaridades do período histórico representado e sofre diretamente os efeitos das crises históricas abordadas, seguindo um modo de representação típico do romance histórico tradicional, conforme a teorização de Georg Lukács (1966). No entanto, a família protagonista criada pelo escritor brasileiro tem como característica a miscigenação biológica, pois seus fundadores têm origens diversas (portugueses, índios, paulistas e açorianos) pelo fato de que a origem miscigenada seria um dos principais elementos da história da formação do Rio Grande do Sul; enquanto que em Yaka Pepetela utiliza uma família de colonos portugueses, aparentemente sem nenhuma marca de miscigenação biológica, sendo que a miscigenação biológica só vai acontecer quando Alexandre Semedo engravida a criada Joana, dando origem a um tronco bastardo na família Semedo. Dentro do tronco principal da família, a mestiçagem que ocorre é a mestiçagem cultural que se dá através da angolanização do patriarca Alexandre Semedo e seu bisneto Joel, que estão colocados estrategicamente nos dois polos da família, como a primeira e a última geração.

\footnotetext{
${ }^{7}$ Em 1979, Manuel Pedro Pacavira publicou Nzinga Mbandi, considerado o primeiro romance histórico angolano.

${ }^{8}$ Lueji, o nascimento dum império (1997), A gloriosa família: o tempo dos flamengos (1999) e A sul. O sombreiro (2011).
} 
Compreende-se essa opção de Pepetela, de ter uma família de colonos portugueses como protagonista em vez de ter uma família de origem miscigenada, por conta de alguns dos objetivos da escrita da obra que, conforme o escritor declarou ao professor Carlos Serrano (1999), visava realizar uma análise da sociedade colonial, procurando revelar a mentalidade do colono e as marcas deixadas pela sociedade colonial na sociedade angolana contemporânea, bem como mostrar a violência do sistema colonial vista por dentro, e também a possibilidade de que alguém que fizesse parte dessa sociedade pudesse angolanizar-se a ponto de participar ativamente da guerra contra os sul-africanos, como fez Joel, o último representante do ramo principal da família Semedo a permanecer em Angola após a independência.

Outra diferença entre os Terra-Cambará, de O tempo e o vento, e os Semedo, de Yaka, é que na narrativa de Erico Verissimo há um contraponto estabelecido entre as figuras masculinas e femininas da família protagonista, que polarizam a trilogia do início ao fim; enquanto que em Yaka a narrativa é centralizada na figura do patriarca Alexandre Semedo, tanto é que o romance começa com o seu nascimento e termina com a sua morte. Embora Alexandre seja um eterno indeciso, as figuras femininas presentes no romance (a esposa, a filha, a nora, as netas) são personagens coadjuvantes que não possuem força suficiente para contrastar com ele.

Também em $O$ tempo e o vento, Erico Verissimo utiliza a técnica narrativa do contraponto para a articulação da história que se passa no sobrado, no tempo sincrônico, com as diversas histórias dos integrantes da família Terra-Cambará passadas no tempo diacrônico, e também para a inserção de outras histórias, que ficaram à margem da narrativa principal, nos episódios intermediários presentes em $O$ continente e $O$ arquipélago, como, por exemplo a história dos Caré, uma família de gaúchos paupérrimos, explorados pelas classes superiores e pelo estado, que representa uma espécie de antissaga familiar em contraposição à história da família TerraCambará. No primeiro caso, a utilização da técnica permite a Erico Verissimo elaborar a narrativa com dois tempos históricos distintos, de forma a quebrar a linearidade da narrativa sem, contudo, prejudicar a sua comunicabilidade e o seu conjunto; e no segundo caso a utilização do recurso permite ao autor inserir na narrativa a história dos excluídos, dos gaúchos pobres e sem história, que ficaram à margem da história oficial, e que sofreram mais do que outros os efeitos das inúmeras guerras e conflitos armados ocorridos no Rio Grande do Sul.

Em Yaka, Pepetela utiliza o contraponto para contar a história sob a perspectiva da família cuvale de Vilonda, uma família que foi massacrada pela polícia colonial portuguesa. A introdução da história dessa família funciona na estrutura da narrativa como uma antissaga em contraste com a família Semedo, representando todos os nativos que sofreram a violência do processo colonial em Angola, tendo papel similar àquele ocupado pelos Caré em $O$ tempo $e$ o vento de Erico Verissimo. A diferença em relação à forma utilizada pelo escritor brasileiro ocorre pelo fato de Pepetela ter se utilizado de uma família nativa, pertencente a um povo que habita a região sul ocidental de Angola e que exerce uma atividade pastora, enquanto Erico Verissimo se vale de uma família tão miscigenada que é praticamente impossível determinar com precisão quais são as suas origens. Também é fator de diferença entre as duas famílias marginais a extensão da abordagem de suas histórias. Pepetela aborda apenas um momento da família Cuvale, fixado na década de 1940, quando ela se cruza com a família Semedo e depois acaba dizimada como vingança pela morte de Aquiles Semedo; enquanto a família Caré figura do início ao fim da trilogia de Erico Verissimo. 
Diferentemente do escritor brasileiro, Pepetela elabora a estrutura narrativa de Yaka de forma linear, focando cinco momentos importantes da história angolana, abordados nas partes “A boca” (1890/1904), “Os olhos” (1917), “O coração” (1940/1941), “O sexo” (1961) e “As pernas” (1975), e a única quebra da linearidade temporal que ocorre é através de uma analepse presente no início da narrativa, quando o narrador antecipa um diálogo entre Alexandre Semedo e seu bisneto Joel que só aconteceria mais de 70 anos depois, no qual o bisavô conta ao bisneto o modo como a estátua yaka veio parar na família.

Mais tarde, já no fim da vida, Alexandre Semedo contou ao bisneto Joel:

- O meu pai ganhou essa estátua yaka no jogo. Já a tinha em Capangombe, quando casou. A minha mãe sempre a achou horrível com estes olhos transparentes de berlinde e estas três listas paralelas, branca, preta e vermelha. Repara, tem quase um metro de altura e corpo de homem, mas a cara é estranha, por vezes com aspecto humano, por vezes animal. O nariz batatudo parece de bêbado e dá um ar trocista ao todo. O meu pai gostava dela, era uma recordação do jogo. (PEPETELA, 1998, p. 34).

Já em relação à polifonia, além de utilizá-la através do diálogo travado entre as personagens, como faz Erico Verissimo que a utiliza para desmitificar a guerra e o mito da democracia racial gaúcha, Pepetela surpreende ao utilizar pelo menos sete narradores, sendo três extremamente significativos: o narrador onisciente em terceira pessoa, Alexandre Semedo e a estátua yaka. Esses três narradores misturam-se no decorrer da narrativa, sendo que às vezes fica difícil até identificar qual voz narrativa está no comando da narração, pois acontece de elas mudarem dentro até de um mesmo parágrafo. Essa multiplicidade de narradores faz com que vejamos um mesmo assunto sempre por duas ou mais perspectivas.

Dentre esses narradores, chama-nos atenção o modo como Pepetela constrói a narrativa pela voz da estátua yaka. Através dela o autor conta a mesma história, mas sob o ponto de vista dos angolanos, construindo uma narrativa angolanizada e em prosa poética, em contraponto às vozes narrativas do narrador em terceira pessoa e de Alexandre Semedo, ao narrar o outro lado da história contada por eles. Da forma como foi elaborada, a história narrada por ela se transforma numa outra história e assim essa polifonia pode ser considerada também como uma narrativa em contraponto, que em certa medida lembra as narrações feitas nos episódios intermediários de $O$ continente, por explicitar no texto a voz da consciência coletiva africana.

Quanto à metaficção, Pepetela não utiliza uma personagem-escritor como faz Erico Verissimo em O tempo e o vento, com a inclusão do romancista Floriano Cambará que se revela ao final da narrativa como o escritor do romance no qual está inserido. Pepetela utiliza como recurso metaficcional as memórias que o patriarca Alexandre Semedo escreve para contar aos seus descendentes como ele e o pai viveram no tempo colonial. Assim, ao tomarmos conhecimento da escrita dessa autobiografia nos damos conta de que, pelo menos, uma parte do romance que estamos lendo é parte integrante das memórias do protagonista, caracterizando-se assim uma mise en abyme ${ }^{9}$.

\footnotetext{
${ }^{9}$ A mise en abyme é definida por Zênia de Faria (2008, p. 6) como um processo metaficcional em que há “[...] a inserção de uma narrativa dentro da outra que apresente uma relação de semelhanças com aquela que contém”, ou seja, que haja uma reduplicação da história contada, de um livro dentro de um outro livro e assim infinitamente, possibilitada pela inclusão de um romancista dentro do romance, que por sua vez escreve um romance que é igual ou semelhante ao que ele é personagem.
} 
Yaka não é a única obra de Pepetela que revela semelhanças com O tempo e o vento. Lueji, o nascimento dum império apresenta o mesmo processo de construção da trilogia, com a utilização de dois tempos históricos (um tempo diacrônico e outro sincrônico) e duas histórias paralelas separadas por quatro séculos, espelhando-se e dialogando o tempo todo. No tempo diacrônico, que corresponde ao passado mítico, a protagonista é a rainha Lunda Lueji, e no tempo sincrônico, a bailarina Lu, uma provável descendente da rainha, que ensaia um bailado para representar a história da soberana Lunda. Além dessa estrutura narrativa em contraponto com duas histórias e dois tempos históricos, essa obra também se caracteriza como uma narrativa de fundação e uma saga familiar e contém uma personagem-romancista, o escritor Dinoluan, que se revela como o autor do próprio romance no qual está inserido, tal qual Floriano Cambará de $O$ tempo e o vento.

No entanto, apesar dessas semelhanças, Lueji, o nascimento dum império se diferencia totalmente de $O$ tempo e o vento e também de Yaka. A família que protagoniza a narrativa é uma família real mítica, e ao contrário dos Semedo ou dos Terra-Cambará, que sofrem as vicissitudes da história, ela é uma agente direta da história. Nesse sentido, Pepetela não faz, na abordagem do passado mítico, uma reconstituição social típica do período e da sociedade abordada, mas sim utiliza a saga de uma família que detém o poder para realizar uma profunda análise do poder, uma análise que não fica restrita ao tempo passado, podendo também ser alusiva ao período de vida do autor, conforme ele mesmo admite em entrevista concedida a Michel Laban (1991). Desse modo, desaparece a forma de representação literária típica do romance histórico tradicional que permeou a escrita de Yaka e entra uma forma de representação literária característica do novo romance histórico e da metaficção historiográfica, conforme os conceitos estabelecidos por Seymour Menton (1993) e Linda Hutcheon (1991), pois, além de ter uma família mítica como protagonista, que equivale a uma família histórica, e de priorizar o questionamento político, a história que se passa no tempo sincrônico questiona o tempo todo a veracidade da história do tempo mítico.

Outra grande diferença em relação a $O$ tempo e o vento é a articulação do contraponto das duas histórias e dos dois tempos históricos. Na trilogia de Erico Verissimo, a mudança de história e de tempo histórico se dá através de uma mudança de capítulo, e em Lueji, o nascimento dum império a mudança tanto de história quanto de tempo histórico acontece, na maioria das vezes, no mesmo parágrafo sem que o leitor sinta o salto sobre os séculos que separam uma história da outra e um tempo do outro, conforme podemos verificar no trecho a seguir:

Timóteo foi embora, prometendo voltar amanhã. Marina descolou da janela, pôs um velho disco de Elias dia Kamezu, vou estudar. Lu puxou o caderno que estava na cabeceira, se pôs a escrever. Sons de marimba e imagens de chanas amarelecidas se baralhavam nas palavras. Talvez também sons amortecidos de palmas batidas ritualmente. Foi isso que despertou Lueji, sentada sozinha na sala de audiências. Levantou vivamente a cabeça e à sua frente estava Kandala, o advinho, saudando. (PEPETELA, 1997, p. 48).

Depois de Lueji, o nascimento dum império, em 1997, Pepetela volta a publicar outra narrativa de fundação, A gloriosa família: o tempo dos flamengos (1999). Nessa obra, que aborda o período da invasão holandesa em Luanda, no século XVII, o autor angolano volta a 
utilizar o recurso da saga familiar, mas se afasta totalmente do modelo estrutural de narrativa de fundação de Erico Verissimo. Na última narrativa de fundação publicada por Pepetela, $A$ sul. O sombreiro, publicada em 2011, ele retoma o uso da técnica narrativa do contraponto para inserir a história do aventureiro Carlos Rocha em contraposição à história do protagonista Manuel Cerveira Pereira, ex-governador da colônia de Angola e fundador de Benguela, e mantém a polifonia narrativa através dos diversos narradores, algo que lhe é característico; mas, a exemplo de A gloriosa família, manteve-se afastado do modelo de Verissimo.

\section{Considerações finais}

Acreditamos que Pepetela tenha se apropriado do modelo de narrativa (romance) de fundação de Erico Verissimo, incorporando e adaptando ao seu projeto literário algumas estratégias de composição utilizadas pelo escritor gaúcho em $O$ tempo e o vento, num período de construção e afirmação da literatura angolana e também de início de carreira do próprio autor, pois foi somente a partir daquele período que ele pôde pensar melhor o seu projeto literário e se afirmar como escritor. Depois dessa fase, Pepetela encontrou outros caminhos para as suas narrativas de fundação.

Assim esperamos ter conseguido mostrar, embora superficialmente, a afinidade ideológica e estética existente entre Erico Verissimo e Pepetela, visível nas narrativas (romances) de fundação O tempo e o vento e Yaka e também em Lueji, o nascimento dum império.

\section{Referências}

ABDALA JÚNIOR, B. Literatura, história e política. 2. ed. Cotia: Ateliê Editorial, 2007.

ANDRADE, J. O galho da nespereira. In: CHAVES, F. L. (org.). O contador de histórias: 40 anos de vida literária de Erico Verissimo. Porto Alegre: Globo, 1972. p. 1-15.

BERGAMO, E. Fiç̧ão e conviç̧ão: Jorge Amado e Neo-realismo português. São Paulo: Editora da Unesp, 2008.

BORDINI, M. G. (org.). A liberdade de escrever: entrevistas sobre literatura e política. Porto Alegre: Editora da UFRGS, EdPUCRS, 1997.

BRAGA, A. Prisioneiros. In: BORDINI, M. G. (org.). A liberdade de escrever: entrevistas sobre literatura e política. Porto Alegre: Editora da UFRGS, EdPUCRS, 1997. p. 27-31.

CANDIDO, A. Literatura e sociedade. 8. ed. São Paulo: T. A. Queiroz, 2000.

CANDIDO, A. A literatura e a formação do homem. Ciência e Cultura, São Paulo, v. 9, n. 24, p. 77-92, 1972.

CANDIDO, A. Brigada Ligeira. 3. ed. Rio de Janeiro: Ouro sobre Azul, 2004.

CHAVES, F. L. O escritor e o seu tempo. Porto Alegre: Ed. UFRGS, 2001. 
CHAVES, R.; MACEDO, T. (org.). Portanto... Pepetela. São Paulo: Ateliê Editorial, 2009.

DENIS, B. Literatura e engajamento: de Pascal a Sartre. Tradução Luiz Dagobert de Aguirra Roncari. Bauru: EDUSC, 2002.

FARIA, Z. Sobre a metaficção e outras estratégias narrativas em A Rainha dos Cárceres da Grécia. In: CONGRESSO INTERNACIONAL ABRALIC, 11., 2008, São Paulo. Anais eletrônicos [...]. São Paulo: ABRALIC, 2008. Disponível em: https://abralic.org.br/eventos/ cong2008/AnaisOnline/simposios/pdf/066/ZENIA_FARIA.pdf. Acesso em: 22 jun. 2021.

HELENA, L. Figuração e questionamento da nação em O tempo e o vento. In: BORDINI, M. da G. (org.). Caderno de pauta simples: Erico Verissimo e a crítica literária. Porto Alegre: Instituto Estadual do Livro, 2005. p. 167-182.

HOWE, I. A política e o romance. Tradução Margarida Goldsztajn. São Paulo: Perspectiva, 1998.

HUTCHEON, L. Poética do pós-modernismo: história, teoria, ficção. Tradução Ricardo Cruz. Rio de Janeiro: Imago, 1991.

KRISTEVA, J. Introdução à semanálise. Tradução Lúcia Helena França Ferraz. São Paulo: Perspectiva, 1974.

LABAN, M. Angola encontro com escritores. Porto: Fundação Antonio Almeida, 1991.

LUKÁCS, G. La novela histórica. México: Era, 1966.

MENTON, S. La nueva novela histórica de la América Latina. 1979-1992. México: FCE, 1993.

PEPETELA. A gloriosa família: o tempo dos flamengos. Rio de Janeiro: Nova Fronteira, 1999.

PEPETELA. A sul. O sombreiro. Lisboa: Dom Quixote, 2011.

PEPETELA. As aventuras de Ngunga. 2. ed. São Paulo: Ática, 1981.

PEPETELA. Lueji, o nascimento dum império. 3. ed. Lisboa: Dom Quixote, 1997.

PEPETELA. Mayombe. São Paulo: Ática, 1982.

PEPETELA. O quase fim do mundo. Lisboa: Dom Quixote, 2008.

PEPETELA. O terrorista de Berkeley, Califórnia. 2. ed. Lisboa: Dom Quixote, 2007.

PEPETELA. Yaka. 4. ed. Lisboa: Dom Quixote, 1998.

SAID, E. Representações do intelectual: as conferências de Reith de 1993. Tradução Milton Hatoum. São Paulo: Companhia das Letras, 2005. 
SARTRE, J. P. Que é literatura? 3. ed. Tradução Carlos Felipe Moisés. São Paulo: Ática, 2006.

SERRANO, C. O romance como documento social: o caso Mayombe. Via Atlântica, São Paulo, n. 3, p. 132-139, 1999.

SILVA, M. I. L. e. A gênese em Incidente em Antares. Porto Alegre: EDIPUCRS, 2000.

TUTIKIAN, J. Entrevista com Pepetela. Organon, Porto Alegre, n. 47, p. 209-211, 2009.

VERISSIMO, E. Caminhos cruzados. 30. ed. São Paulo: Globo, 1995a.

VERISSIMO, E. Clarissa. 50. ed. São Paulo: Globo, 1995 b.

VERISSIMO, E. Incidente em Antares. 25. ed. São Paulo: Globo, 1995c.

VERISSIMO, E. Música ao longe. 32. ed. São Paulo: Globo, 1995d.

VERISSIMO, E. O arquipélago. 18. ed. São Paulo: Globo, 1995e. 3 v.

VERISSIMO, E. O continente. 34. ed. São Paulo: Globo, 1995f. 2 v.

VERISSIMO, E. O prisioneiro. 12. ed. São Paulo: Globo, 1995g.

VERISSIMO, E. O retrato. 18. ed. São Paulo: Globo, 1995h. 2. v

VERISSIMO, E. O senhor embaixador. 14. ed. São Paulo: Globo, 1995i.

VERISSIMO, E. Saga. 15. ed. São Paulo: Globo, 1995j.

VERISSIMO, E. Um lugar ao sol. 30. ed. São Paulo: Globo, 1995k.

ZHIRMUNSKY, V. Sobre o estudo da literatura comparada. Tradução Ruth Percice Nogueira. In: COUTINHO, E. F.; CARVALHAL, T. Literatura comparada: textos fundadores. Rio de Janeiro: Rocco, 1994. p. 199-214. 